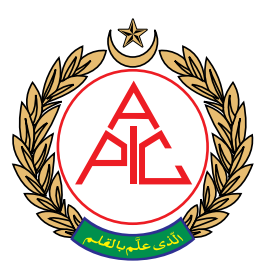

Professor of Anesthesiology, Aga Khan University Hospital, Stadium Road, Karachi

(Pakistan)

Correspondence:

Fauzia Anis Khan,

Department of Anaesthesiolgy,

Aga Khan University, P.O Box

3500, Stadium Road,

Karachi 74800, (Pakistan);

Mobile: 00923008295385;

E-mail: fauzia.khan@aku.edu

Received: 8 December 2019;

Reviewed \& Accepted: 12

December 2019

\section{Anesthetic drugs shortage in lower and middle income countries: a safety and quality issue}

\author{
Fauzia Anis Khan, FRCA
}

\begin{abstract}
Drug shortage is now a universal problem; but shortage of anesthetic drugs particularly can have wide implications on patient safety. The available data on the magnitude of the problem in lower and middle income countries (LMIC) is very limited. Several factors, e.g. manufacturing and regulatory issues, supply chain issues, hoarding and smuggling can cause shortage of these drugs. Drug shortage results in substitution, increased side effects and medication errors. It also has cost implications. Different models have been recommended to handle these shortages. Innovative solutions require action at all levels, ranging from individuals, institutions, pharmaceutical companies, professional societies, and the governments.
\end{abstract}

Key words: Drug availability, Safety; Lower and middle income countries

Citation: Khan FA. Anesthetic drugs shortage in lower and middle income countries: a safety and quality issue. Anaesth pain \& intensive care 2019;23(4);337-339.

DOI: https://doi.org/10.35975/apic.v23i4.1164
Drug shortage related to healthcare is not a new phenomenon and anesthesia as a specialty is not immune in this regard. ${ }^{1}$ There is no standardized definition available. The European Federation of Pharmaceutical Industry Association (EFPIA) defines it as "The occurrence of internal or external situation (or a combination of both) which could result in an interruption of supplies of a medical product, if not properly controlled". ${ }^{2}$

Whereas, previously it was considered a lower and middle income countries (LMIC) problem, but now it has been reported even from high income countries (HIC) and has quality and financial implications at a global scale. In a European survey $21 \%$ of pharmacists reported facing drug shortage almost every day. Anesthesia is a specialty where shortage of anesthetic drugs can have significant effects on patient safety. ${ }^{4}$

\section{Magnitude of Problem in LMIC}

There is little data available from LMIC. A paper published from Uganda in 2007 stated that narcotics were "always available" in $45 \%$, nondepolarizing muscle relaxant in $15 \%$, inhalational agent in $38 \%$, and induction agent in $59 \%$ of the anesthetics. ${ }^{5}$ In an editorial published in 2012 in this journal, non-availability of some of the essential drugs in
Pakistan was pointed out. These included narcotics, inhalational agents, induction agents and some vasoactive drugs. ${ }^{6}$

\section{Causes of Drug Shortage in LMIC}

There are several factors that contribute to the drug shortage including anesthetic drugs. Some of the reasons are common to both HIC and LMIC, but there are many additional issues effecting LMICs. Some of the factors in HICs are regulatory issues, manufacturing problems, raw material acquisition problems, business decisions based upon the profitability of some drugs, and disturbances or faults in supply chain. ${ }^{7}$ In LMIC there are additional issues of licensing by healthcare regulatory authorities, and import from abroad, shortage of ingredients for local manufacture, boarding tax government policies and drug smuggling to other countries. ${ }^{8}$

\section{Consequences of Drug Shortages}

\section{Safety Issues}

Drug shortage results in substitution, which brings up the issue of drug integrity of substituted drugs. It is difficult to trace the appropriate handling and shortage of these substituted drugs. The substituted drugs may also be of reduced efficacy and may have 


\section{medication shortage}

increased side effects. Substitution also results in a higher incidence of medication errors. ${ }^{9}$ It may result in cancellation of surgery which may be emotionally traumatic to both patients and their families.

\section{Cost implication}

Shortage has cost implication for both patients and hospitals. Cancellation of surgery prolongs hospital stay and exposes the patient to higher risk of hospital acquired infections. In addition, the substituted drugs may be more expensive. Hospitals in order to accommodate product changes may need to hire more pharmacists or may have to compensate them by offering overtime allowance to staff. ${ }^{10}$

\section{Other Issues}

In addition to safety and cost implications there may be some other issues, like problems with clinical research, which demands a protocolized approach to anesthetic management. It may also lead to counterfeiting as substituted drugs may need to be purchased from a grey market of unauthorized supply channel.

\section{Managing Drug Shortage}

Different models to deal with drug shortages have been discussed in different countries. One of these is a risk based approach. This approach requires the hospitals or purchasing authorities to categorize the criticality of shortage in terms of patient impact and assess alternative therapies. ${ }^{11}$ They also need to assess the probability shortage based on sources of manufacture, weaker links in supply /demand chain and inventory and then make decision on how to control and manage the risk to patient safety and product. This can also be tackled at different levels. ${ }^{12}$

\section{Role of individuals:}

There are a few things that an anesthesiologist can do in his/her individual practice. One example is by reducing wastage especially of drugs that are vulnerable to shortage e.g. with double syringe technique. Also, to use regional techniques wherever feasible, and develop experience with alternative drugs. This in turn may require data generation and publication if enough publications on use of these alternatives is not available.

\section{Role of Teaching Hospitals:}

Teaching hospitals can play their part by teaching and training residents both in use of alternate drugs and techniques. Regional anesthesia techniques should be an essential part of training curricula in LMIC.

\section{Role of Pharmacy:}

All pharmacies need to have action plans or a shortage policy to deal with drug shortages, continuous monitoring and implementation of the action plan if shortage occurs and reversal of all actions when shortage resolves. They also need to be in communication with all stake holders. ${ }^{10}$

The pharmacy action plans are generally based on three points:

a) Conservation i.e. restriction of drugs that are prone to shortage and only release them on per need basis.

b) Substitution i.e. to consider therapeutic alternatives with equivalent doses, adverse effect profile, pharmacokinetics and contra-indications.

c) Adaptation which involves increasing institutional awareness, setting up advanced warning systems and modification of purchase amounts.

\section{Role of Professional Societies:}

Professional societies can play a role to put pressure upon the concerned authorities regarding their policies and also by means of press releases from time to time. Another area in which anesthesia societies can help is in formulating 'Essential drug lists'. In 2015 Association of Anesthetists of UK \& Ireland published an essential anestheisa drug list. ${ }^{12}$ The list is divided into essential drugs, necessary drugs and critical drugs. Essential drugs are considered minimum need for a health system. Necessary are needed to prevent serious conditions where no alternative is available. Critical drugs are both necessary and vulnerable to shortage.

WHO also has a model list of 'Essential Medicines' which includes some anesthetic drugs. ${ }^{13}$ This list is updated from time to time and was last updated in 2019.

\section{Role of Manufacturers:}

Manufacturers also need to develop systems to proactively identify and resolve quality issues across their supply chains and have flexible policies regarding production and availability.

\section{Role of Governments:}

Governments have an overarching role. This includes alteration of drug related policies, giving monitory incentives for "unprofitable drugs", regional cooperation at government levels and also establishing national reporting systems for drug shortages.

\section{CONCLUSION}

The problem of drug shortage is a complex one and involves several stake holders. A coordinated approach across the healthcare systems is needed. Strategies need to be identified at all levels and put in practice.

Conflict of interest: None declared by the author. 
editorial view

\section{REFERENCES}

1. Medicine shortages. Global 5. Hoidges SC, Mijumbi C, Okello M, approaches to addressing shortages of essential medicines in health systems. WHO drug Information. 2016:30;180-185. [Free Full Text]

2. European Federation of Pharmaceutical Industries and Associations (EFPIA). EFPIA Good Practice-Oct 2013-Reducing Risk for Drug Products Shortages, No: October 1-6. Available at: http://www.efpia.eu/ uploads/Modules/Mediaroom/ gshortagegoodpracticeoct2013.pdf.

3. European Association of Hospital Pharmacists (EAHP). Medicines shortages in European hospitals. The evidence and case for action. October 2014. Available at: https://www.eahp. eu/press-room/patients-sufferingmedicines-shortages-all-europeancountries. Accessed on: 26/11/2019

4. De-Olevier GS, Theilken LS, McCarthy RJ. Shortage of perioperative drugs: implications for anesthesia practice and patient safety. Anesth Analg. 2011;113:1429-35. [Pubmed] doi: 10.1213/ANE.0b013e31821f23ef. McCormick BA, Walker IA, Wilson $\mathrm{IH}$.. Anesthesia services in developing countries: defining the problems. Anaesthesia. 2007;62:4-11. [Pubmed]

6. Khan TH. Availability of essential drugs in Pakistan (Editorial). Anaesth pain \& intensiv care. 2009;13:1-3. [Free Full Text]

7. ASHP Expert Panel on Drug Product Shortages, Fox ER, Birt A, James KB, Kokko $H$, Salverson S, et al. ASHP guidelines on managing drug product shortages in hospitals and health systems. Am J Health-Syst Pharm. 2009;66:1399-1406. [Pubmed] doi: 10.2146/ajhp090026.

8. Atif M, Malik I, Mushtaq I, Asghar S. Medicine shortages in Pakistan. A qualitative study to explore current situation, reasons and possible solutions to overcome the barriers. BMJ Open. 2019;9:e027028. [Pubmed] [Free Full Text] doi: 10.1136/bmjopen-2018-027028.

9. Traynor K. Drug shortages mount in 2010. Am J Health-Syst Pharm. 2010;67:1492-1494. [Pubmed] doi: 10.2146/news100064.

10. Caulder CR, Mehta B, Stevenson B, Bookstaver PB, Sims LD. Impact of drug shortages on health system pharmacies in South Eastern United States. Hosp Pharm. 2015;50:27886. [Pubmed] [Free Full Text] doi: 10.1310/hpj5004-279.

11. Raminarine $E$, Ronninger $S$, Vinther A. Preventing and managing drug shortages. Available at: http:// www.pda.org/publications/pdapublications/pda-letter/latestnews/2014/04/29/. Accessed on: 22 November 2019

12. Harrop-Griffiths W. The National Essential Anaesthesia Drug List. Anaesthesia 2015;70;650-53. [Pubmed] [Free Full Text]

13. 21st WHO Model List of Essential Medicines 2019. Available at: https://apps.who.int/iris/bitstream/ handle/10665/325771/WHO-MVPEMP-IAU-2019.06-eng.pdf?ua =1. Accessed on: 22 November 2019 